\title{
Current Immune-Related Molecular Approach in Combating Nasopharyngeal Cancer
}

\author{
Soehartati A. Gondhowiardjo ${ }^{\mathrm{a}, \mathrm{b}}$, Marlinda Adham ${ }^{\mathrm{a}, \mathrm{c}}$, Lisnawati ${ }^{\mathrm{a}, \mathrm{d}}$, Henry Kodrat ${ }^{\mathrm{a}, \mathrm{b}}$, \\ Demak Lumban Tobing ${ }^{\mathrm{e}}$, Handoko ${ }^{\mathrm{a}, \mathrm{b}}$, f, I. Made Haryoga ${ }^{\mathrm{a}, \mathrm{b}}$, \\ Agustinus Gatot Dwiyono, ${ }^{\mathrm{a}, \mathrm{b}}$, Yoseph Adi Kristian ${ }^{\mathrm{a}, \mathrm{b}}$
}

\begin{abstract}
Nasopharyngeal cancer is a cancer closely related to Epstein-Barr virus (EBV) infection. EBV protein has been shown to be related to various oncogenic development. Suppression of tumor suppressor genes, upregulating molecules to prevent immune attack, downregulating pro-apoptotic proteins, and stimulating local immune suppressive environment are among some roles that EBV proteins can exert on host cells. All those factors combined together with underlying genetic susceptibility of host cells further increase the chance of nasopharyngeal cancer development. Approach targeting those carcinogenesis pathways has been tested with marginal benefit. A newer approach boosting immune cells to increase recognition of tumor antigen and promoting cytotoxic $\mathrm{T}$ cell attack has shown promising clinical benefit. Further combination of those immunotherapies with other modality, in particular radiotherapy, has resulted in amplification of cancer killing.
\end{abstract}

Keywords: Carcinogenesis; EBV; Immunotherapy; Nasopharyngeal cancer; PD-L1

\section{Introduction}

Nasopharyngeal cancer has a low incidence rate worldwide,

Manuscript submitted June 18, 2019, accepted July 4, 2019

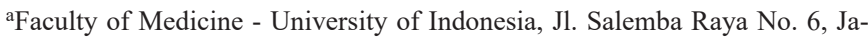
karta 10430, Indonesia

bDepartment of Radiotherapy Cipto Mangunkusumo Hospital, Jl. Diponegoro No. 71, Jakarta 10430, Indonesia

'Department of ENT, Cipto Mangunkusumo Hospital, Jl. Diponegoro No. 71, Jakarta 10430, Indonesia

${ }^{\mathrm{d} D e p a r t m e n t}$ of Anatomical Pathology, Faculty of Medicine - University of Indonesia, Jl. Salemba Raya No. 6, Jakarta 10430, Indonesia

eDepartment of Clinical Pathology, Dharmais Cancer Hospital, Jl. Letjen Jend. S. Parman No.84-86 Jakarta 11420, Indonesia

${ }^{f}$ Corresponding Author: Handoko, Faculty of Medicine - University of Indonesia, Jl. Salemba Raya No. 6, Jakarta 10430, Indonesia and Department of Radiotherapy Cipto Mangunkusumo Hospital, Jl. Diponegoro No. 71, Jakarta 10430, Indonesia. Email: pori.iros@yahoo.com

doi: https://doi.org/10.14740/wjon1214 which comprises just $0.7 \%$ of all cancer globally in 2018 [1]. However, in some regions such as Southeast Asia and southern Asia, nasopharyngeal cancer is an endemic cancer with a high mortality rate [2]. Metastatic disease and diagnosis in advanced stage contributed to those high mortality rates in those endemic regions [2].

Nasopharyngeal cancer in its early stage is a manageable cancer with relatively good prognosis. Even in case of locally advanced stage, nasopharyngeal cancer treated with concurrent chemoradiotherapy could reach up to $87 \%$ locoregional control rate in 10 years [3]. Major cause of treatment failure is distant metastasis $[4,5]$. Survival of those relapsed and metastatic nasopharyngeal cancer remains poor [5] despite the advancement in various aspects in systemic therapies.

Current and past researches have put a great focus in understanding the biology of nasopharyngeal cancer with hope to find various effective major targets that can potentially be targeted to inhibit the growth of cancer cells. Exploring the pathogenesis of nasopharyngeal cancer and devising molecules to block those abnormal signaling molecules were proposed in the last several decades. That kind of targeted therapy approach seemed to be very promising in inhibiting the growth of cancer cells. However, the results of that targeted therapy, such as anti-epidermal growth factor receptor (EGFR) [6], and anti-Epstein-Barr virus (EBV) viral proteins [7], have been proven to be only mildly effective with just modest to no survival benefit.

Another systemic strategy, which focused on employing self-immune system in combating cancer, is being explored with a remarkable success rate in various cancers. In some subsets of cases, immunotherapy could even reach complete remission or significantly prolonged survival [8-11]. Based on those successes, currently there are a lot of studies ongoing to explore and understand more about immunotherapy.

Furthermore, nasopharyngeal cancer varies greatly from region to region. In Western countries, not just is the incidence low, but also the most common histology is keratinized WHO type I and II nasopharyngeal cancer $[12,13]$. Whereas in Eastern countries, such as Indonesia, almost all of the nasopharyngeal cancer histology in Indonesian population was non-keratinized undifferentiated histology WHO type III [14].

The pathogenesis of undifferentiated nasopharyngeal cancer is EBV-related. Virus-related cancer is supposed to be more immunogenic; thus this kind of cancer will present with a distinct tumor biology which requires understanding of its 
pathogenesis. Devising immune-related target to combat this kind of cancer will require slightly different approach. This review will focus on a specific overview about immune-related molecular approach in combating nasopharyngeal cancer especially in those with EBV infection.

\section{Role of EBV in Nasopharyngeal Cancer}

Nasopharyngeal cancer, in particular non-keratinized undifferentiated histology, is closely related with EBV infection. EBV DNA was found in almost all undifferentiated nasopharyngeal carcinoma specimen $[15,16]$. EBV infection in pharyngeal epithelial progresses from lytic infection to latent infection [17]. The latter has been proven to be closely related with the carcinogenesis of nasopharyngeal cancer [17].

Despite in latent mode, EBV in nasopharyngeal cancer cells continued to express various viral proteins such as the EBV nuclear antigen 1 (EBNA1), latent membrane protein 1 (LMP1), LMP2A, and LMP2B [18]. Those viral proteins served to maintain a balanced viral replication, sufficient enough to maintain viral latent infection while at the same time limited protein expression to prevent presentation of viral antigen to immune system [19]. Almost all latent EBV proteins were oncogenic but weakly immunogenic [18].

EBV proteins are oncogenic due to its ability to inactivate host tumor suppressor gene and interact with host cellular gene expression regulator to upregulate gene associated with pro-survival. EBV LMP1 in nasopharyngeal cancer has been shown to promote methylation at phosphatase and tensin homolog (PTEN) promoter site, thus silencing this important tumor suppressor gene in human [20]. EBNA1 has been shown to be associated with multiple chromosomal binding sites, which modulate multiple pro-survival gene expression [19].

EBV infection alone is not sufficient to promote cancer growth in nasopharynx. Underlying genetic makeup, variations of human leukocyte antigen (HLA) complex on chromosome 6 have been linked to increased susceptibility of certain individuals contracting nasopharyngeal cancer [17, 21, 22]. Apart from that, possible inherent loss of heterozygosity on chromosomes 3p, 9p, and 14q [23], which coded for tumor suppressor genes, further increases the probability of developing abnormal cancer cells.

Further somatic mutation in the initial loss of heterozygosity genes transformed the epithelial cells into precancerous cells. Various whole exome and whole genome studies have confirmed the association between those tumor suppressor genes, such as p16, RASSF1A, and MST1R with increased risk of nasopharyngeal cancer [24-26]. Those tumor suppressor genes could be inactivated by direct somatic mutation to the gene sequence or hypermethylation at its promoter site by various EBV proteins, thus inactivating those essential tumor suppressor genes and transforming those cells to become precancerous cells.

Recent studies indicated the role of microRNAs in further transforming cells into malignant phenotype. Specifically, in nasopharyngeal cancer, EBV genome contains multiple regions coded for microRNAs [27]. EBV microRNAs have been shown to control EBV protein expression such as LMP1 [28].
Furthermore, EBV microRNAs modulate various host gene expression, such as by promoting anti-apoptotic proteins [27, 29]. With all those factors interplaying together in concert, epithelial cells initially at risk and infected by EBV could develop in cancerous cells.

\section{Escaped Immune Surveillance as Nasopharyn- geal Cancer Progresses}

In normal condition, cells infected by virus will present the viral antigen through major histocompatibility complex (MHC) Class I complex thereby attracting cytotoxic $T$ cells to eliminate the infection. However, in EBV infection in epithelial pharyngeal cells, there are multiple EBV proteins, such as BCRF1, BILF and BNLF2a, which work to inhibit antigen presentation processes $[30,31]$. Those viral proteins make EBV downregulate MHC Class I complex and make EBV antigens process poorly, thus resulting in immune escape.

Even in case of successful presentation of antigens to the immune system, cancer cells are able to escape immune attack by expressing immune checkpoint molecules. Nasopharyngeal cancer is a cancer with high expression of programmed death ligand 1 (PD-L1) molecule [32, 33], one of the most extensively studied checkpoint molecule on cancer cells. Increased PDL1 expression in nasopharyngeal cancer has been shown to be associated with LMP1 EBV protein [34]. Interaction of PD-L1 in cancer cells and PD-1 in T lymphocytes leads to downregulation of immune response, thereby preventing attack of cancer cells by cytotoxic $\mathrm{T}$ cells.

Complicating the situation, cancer cells are able to downplay pro-inflammatory signals. There is evidence indicating local tumor microenvironment milieu bathed with immune suppression signals in nasopharyngeal cancer [35-37]. Despite high level of tumor infiltrating cytotoxic and helper $\mathrm{T}$ cells in nasopharyngeal cancer [38], attack of cancer cells remains blunted due to chemokines secreted by cancer cells such as CCL20 $[18,36]$. CCL20 is a chemokine that functions to recruit $\mathrm{T}$ regulatory cells, a subset of $\mathrm{T}$ cells that counter-regulate inflammation.

With all those mechanisms in EBV-associated nasopharyngeal cancer, it is not surprising that though the cancer cells contain viral antigen, it is still able to escape immune surveillance. Tremendous efforts have been made in recent decades to understand and explore the possibility in interfering some or all of those mechanisms that downplay immune response. A few current works of the aforementioned strategy will be discussed in the next section.

\section{Current Works in Progress for Potential Im- mune-Related Target Blockage in Nasopharyn- geal Cancer}

Based on the understanding of EBV-associated nasopharyngeal cancer pathogenesis and mechanism of immune escape, several novel approaches can be employed to combat nasopharyngeal cancer. Targeting pathways that lead to cancer 
progression such as targeting EBV proteins or blocking downstream pathway that promotes survival may be an option, but this approach seems to only retard cancer cells progression and does not specifically result in cancer cell death. Another approach by targeting pathways that modulate immune system in attempt to increase viral or tumor antigen presentation, blocking immune checkpoint, or blocking immune suppression seems to lead to a better result.

Immune checkpoint inhibitor has shown activity in several trials in nasopharyngeal cancer $[39,40]$. Result of phase 1 KEYNOTE-028 study, which administered pembrolizumab (anti-PD-1) to recurrent or metastatic nasopharyngeal cancer, indicated beneficial effect in 21 out of 27 patients who experienced stable to partial response over a period of 20 months [39]. The preliminary result of phase 2 trial with tislelizumab (an anti-PD-1) which was presented in ASCO 2019 meeting showed $43 \%$ objective response rate and 10.4 months of progression-free survival (PFS) in those with advanced metastatic or recurrent nasopharyngeal cancer. This was shown to confer longer PFS compared to historical control (PFS of 7 months) with second-line chemotherapy [41]. However, the survival benefit is yet to be proven in phase 3 study.

Another study administering nivolumab (anti-PD-1) to treat recurrent and metastatic nasopharyngeal cancer resulted in one patient experiencing complete response [40]. Though 1-year overall survival remained low, survival was just $59 \%$ in that nivolumab study [40]. The possibility of complete response after immune checkpoint inhibitor indicated that blocking that immune checkpoint axis was on the right path, but immune checkpoint inhibitor alone was not enough to enable immune cells to fully eradicate cancer cells.

Another strategy to increase cancer cells killing by immune cells is to incorporate radiotherapy with immune checkpoint inhibitor. Radiation has been proven to induce upregulation of tumor antigen $\mathrm{MHC}$ Class I complex, thereby increasing antigen presentation $[42,43]$. Radiation also results in cancer cell deaths, thus releasing tumor neoantigen which then was phagocytized, processed and presented by dendritic cells to $\mathrm{T}$ helper [43]. Overall, radiation to cancer cells results in increased presentation of tumor neoantigen to immune system. However, at the same time, cancer cells upregulate immune molecule which is immunosuppressive. Therefore, combined immune checkpoint inhibitor and radiotherapy will overcome mechanism of resistance when individual treatment is employed.

Various pre-clinical studies and case reports have shown tremendous benefit directly or indirectly in combination of immune checkpoint inhibitor with radiotherapy. Radiation has been shown to upregulate PD-L1 expression in vitro and in vivo in pre-clinical model [44, 45]. Early clinical evidence, currently based on case reports in recurrent metastatic nasopharyngeal cancer, showed durable response even in case of distant failure in heavily pre-treated nasopharyngeal cancer. Two cases, one with pembrolizumab and the other with nivolumab, underwent sequential combination of immunotherapy with radiotherapy showed complete response after all other conventional treatment has failed [46, 47]. Radiotherapy was sandwiched between immunotherapy in those cases.

Other possible immune-related approach to combat naso- pharyngeal cancer is $\mathrm{T}$ regulatory depletion, cancer vaccine, and adoptive $\mathrm{T}$ cell transfer. In Treg depletion, various monoclonal antibodies directed against Treg or various chemokines that promote Treg differentiation can be used. However, most studies in Treg depletion are still in pre-clinical setting [48, 49]. More data will be required before it can enter clinical studies, because there are still conflicting results in this Treg depletion studies. In cancer vaccine and adoptive T cell transfer, EBV latent protein antigens are commonly employed as the target. Most of the studies in cancer vaccine and adoptive $\mathrm{T}$ cell transfer are still in phase I/II studies [50-52]; however they have shown some interesting signs of clinical benefit in selected population.

\section{Conclusions}

In recent decades, cancer treatment paradigm has shifted its focus from targeting pathway of carcinogenesis to modulating immune system to enhance immune attack directed toward cancer cells. The immunotherapy seems to offer a greater hope. Although as solo treatment, complete and durable response was only observed in a very limited number of cases. When combined with other modalities, in particular radiotherapy, enhanced response was observed. Especially in nasopharyngeal cancer, where cancer carcinogenesis is closely related to EBV infection, the molecular to biological landscape might be somewhat different. Therefore, a better understanding and trials are required to fully explore this immunotherapy capability or its combination toward combating nasopharyngeal cancer.

\section{Acknowledgments}

None to declare.

\section{Financial Disclosure}

There is no financial funding for this review article.

\section{Conflict of Interest}

None to declare.

\section{Author Contributions}

SAG contributed to main conception and final proofreading. Handoko contributed to main drafting and revisions. All other authors contributed equally to sections of the article.

\section{References}

1. Bray F, Ferlay J, Soerjomataram I, Siegel RL, Torre LA, Jemal A. Global cancer statistics 2018: GLOBOCAN es- 
timates of incidence and mortality worldwide for 36 cancers in 185 countries. CA Cancer J Clin. 2018;68(6):394424.

2. Salehiniya H, Mohammadian M, Mahdavifar N. Nasopharyngeal cancer $\mathrm{nn}$ the world: epidemiology, incidence, mortality and risk factors. World Cancer Res J. 2018;5(1):1-8.

3. Lee AWM, Tung SY, Ng WT, Lee V, Ngan RKC, Choi HCW, Chan LLK, et al. A multicenter, phase 3, randomized trial of concurrent chemoradiotherapy plus adjuvant chemotherapy versus radiotherapy alone in patients with regionally advanced nasopharyngeal carcinoma: 10-year outcomes for efficacy and toxicity. Cancer. 2017;123(21):4147-4157.

4. Kong FF, Ying H, Du CR, Huang S, Zhou JJ, Hu CS. Effectiveness and toxicities of intensity-modulated radiation therapy for patients with T4 nasopharyngeal carcinoma. PLoS One. 2014;9(3):e91362.

5. Frezza G, Barbieri E, Emiliani E, Silvano M, Babini L. Patterns of failure in nasopharyngeal cancer treated with megavoltage irradiation. Radiother Oncol. 1986;5(4):287294.

6. Peng H, Tang LL, Liu X, Chen L, Li WF, Mao YP, Zhang $\mathrm{Y}$, et al. Anti-EGFR targeted therapy delivered before versus during radiotherapy in locoregionally advanced nasopharyngeal carcinoma: a big-data, intelligence platformbased analysis. BMC Cancer. 2018;18(1):323.

7. Stoker SD, Novalic Z, Wildeman MA, Huitema AD, Verkuijlen SA, Juwana H, Greijer AE, et al. Epstein-Barr virus-targeted therapy in nasopharyngeal carcinoma. J Cancer Res Clin Oncol. 2015;141(10):1845-1857.

8. Kollipara R, Schneider B, Radovich M, Babu S, Kiel PJ. Exceptional Response with Immunotherapy in a Patient with Anaplastic Thyroid Cancer. Oncologist. 2017;22(10):1149-1151.

9. Cabel L, Loir E, Gravis G, Lavaud P, Massard C, Albiges L, Baciarello G, et al. Long-term complete remission with Ipilimumab in metastatic castrate-resistant prostate cancer: case report of two patients. J Immunother Cancer. 2017;5:31.

10. Robert C, Thomas L, Bondarenko I, O'Day S, Weber J, Garbe $C$, Lebbe $C$, et al. Ipilimumab plus dacarbazine for previously untreated metastatic melanoma. N Engl J Med. 2011;364(26):2517-2526.

11. Hodi FS, O'Day SJ, McDermott DF, Weber RW, Sosman JA, Haanen JB, Gonzalez R, et al. Improved survival with ipilimumab in patients with metastatic melanoma. N Engl J Med. 2010;363(8):711-723.

12. Colaco RJ, Betts G, Donne A, Swindell R, Yap BK, Sykes AJ, Slevin NJ, et al. Nasopharyngeal carcinoma: a retrospective review of demographics, treatment and patient outcome in a single centre. Clin Oncol (R Coll Radiol). 2013;25(3):171-177.

13. Ruuskanen M, Grenman R, Leivo I, Vahlberg T, Makitie A, Saarilahti K, Wigren T, et al. Outcome of nasopharyngeal carcinoma in Finland: A nationwide study. Acta Oncol. 2018;57(2):251-256.

14. Adham M, Kurniawan AN, Muhtadi AI, Roezin A, Hermani B, Gondhowiardjo S, Tan IB, et al. Nasopharyn- geal carcinoma in Indonesia: epidemiology, incidence, signs, and symptoms at presentation. Chin J Cancer. 2012;31(4):185-196.

15. Klein G, Giovanella BC, Lindahl T, Fialkow PJ, Singh S, Stehlin JS. Direct evidence for the presence of EpsteinBarr virus DNA and nuclear antigen in malignant epithelial cells from patients with poorly differentiated carcinoma of the nasopharynx. Proc Natl Acad Sci U S A. 1974;71(12):4737-4741.

16. Fahraeus R, Fu HL, Ernberg I, Finke J, Rowe M, Klein $\mathrm{G}$, Falk K, et al. Expression of Epstein-Barr virus-encoded proteins in nasopharyngeal carcinoma. Int J Cancer. 1988;42(3):329-338.

17. Tsao SW, Tsang CM, Lo KW. Epstein-Barr virus infection and nasopharyngeal carcinoma. Philos Trans R Soc Lond B Biol Sci. 2017;372(1732).

18. Jain A, Chia WK, Toh HC. Immunotherapy for nasopharyngeal cancer-a review. Chin Clin Oncol. 2016;5(2):22.

19. Wilson JB, Manet E, Gruffat H, Busson P, Blondel M, Fahraeus R. EBNA1: oncogenic activity, immune evasion and biochemical functions provide targets for novel therapeutic strategies against Epstein-Barr Virus- associated cancers. Cancers (Basel). 2018;10(4):109.

20. Peng H, Chen Y, Gong P, Cai L, Lyu X, Jiang Q, Wang $\mathrm{J}$, et al. Higher methylation intensity induced by EBV LMP1 via NF-kappaB/DNMT3b signaling contributes to silencing of PTEN gene. Oncotarget. 2016;7(26):4002540037.

21. Yang H, Yu K, Zhang R, Li J, Wei X, Zhang Y, Zhang $\mathrm{C}$, et al. The HLA-DRB1 allele polymorphisms and nasopharyngeal carcinoma. Tumour Biol. 2016;37(6):71197128.

22. Bei JX, Zuo XY, Liu WS, Guo YM, Zeng YX. Genetic susceptibility to the endemic form of NPC. Chin Clin Oncol. 2016;5(2):15.

23. Lo KW, Teo PM, Hui AB, To KF, Tsang YS, Chan SY, Mak KF, et al. High resolution allelotype of microdissected primary nasopharyngeal carcinoma. Cancer Res. 2000;60(13):3348-3353.

24. Lo KW, Huang DP, Lau KM. p16 gene alterations in nasopharyngeal carcinoma. Cancer Res. 1995;55(10):20392043.

25. Wang T, Liu H, Chen Y, Liu W, Yu J, Wu G. Methylation associated inactivation of RASSF1A and its synergistic effect with activated K-Ras in nasopharyngeal carcinoma. J Exp Clin Cancer Res. 2009;28:160.

26. Dai W, Zheng H, Cheung AK, Tang CS, Ko JM, Wong $\mathrm{BW}$, Leong MM, et al. Whole-exome sequencing identifies MST1R as a genetic susceptibility gene in nasopharyngeal carcinoma. Proc Natl Acad Sci U S A. 2016;113(12):3317-3322.

27. Spence T, Bruce J, Yip KW, Liu FF. MicroRNAs in nasopharyngeal carcinoma. Chin Clin Oncol. 2016;5(2):17.

28. Lo AK, To KF, Lo KW, Lung RW, Hui JW, Liao G, Hayward SD. Modulation of LMP1 protein expression by EBV-encoded microRNAs. Proc Natl Acad Sci U S A. 2007;104(41):16164-16169.

29. Kuzembayeva M, Hayes M, Sugden B. Multiple func- 
tions are mediated by the miRNAs of Epstein-Barr virus. Curr Opin Virol. 2014;7:61-65.

30. Fares S, Spiess K, Olesen ETB, Zuo J, Jackson S, Kledal TN, Wills MR, et al. Distinct roles of extracellular domains in the epstein-barr virus-encoded BILF1 receptor for signaling and major histocompatibility complex class I downregulation. MBio. 2019;10(1):e01707-18.

31. Jochum S, Moosmann A, Lang S, Hammerschmidt W, Zeidler R. The EBV immunoevasins vIL-10 and BNLF2a protect newly infected $\mathrm{B}$ cells from immune recognition and elimination. PLoS Pathog. 2012;8(5):e1002704.

32. Zhang J, Fang W, Qin T, Yang Y, Hong S, Liang W, Ma $\mathrm{Y}$, et al. Co-expression of PD-1 and PD-L1 predicts poor outcome in nasopharyngeal carcinoma. Med Oncol. 2015;32(3):86.

33. Zhou Y, Miao J, Wu H, Tang H, Kuang J, Zhou X, Peng Y, et al. PD-1 and PD-L1 expression in 132 recurrent nasopharyngeal carcinoma: the correlation with anemia and outcomes. Oncotarget. 2017;8(31):51210-51223.

34. Fang W, Zhang J, Hong S, Zhan J, Chen N, Qin T, Tang $\mathrm{Y}$, et al. EBV-driven LMP1 and IFN-gamma up-regulate PD-L1 in nasopharyngeal carcinoma: Implications for oncotargeted therapy. Oncotarget. 2014;5(23):1218912202.

35. Liu P, Xie BL, Cai SH, He YW, Zhang G, Yi YM, Du J. Expression of indoleamine 2,3-dioxygenase in nasopharyngeal carcinoma impairs the cytolytic function of peripheral blood lymphocytes. BMC Cancer. 2009;9:416.

36. Mrizak D, Martin N, Barjon C, Jimenez-Pailhes AS, Mustapha R, Niki T, Guigay J, et al. Effect of nasopharyngeal carcinoma-derived exosomes on human regulatory $\mathrm{T}$ cells. J Natl Cancer Inst. 2015;107(1):363.

37. Ma J, Xuan SH, Li Y, Zhang ZP, Li XH. Role of the TGFbeta/PDCD4/AP-1 signaling pathway in nasopharyngeal carcinoma and its relationship to prognosis. Cell Physiol Biochem. 2017;43(4):1392-1401.

38. Ooft ML, van Ipenburg JA, Braunius WW, Zuur CI, Koljenovic S, Willems SM. Prognostic role of tumor infiltrating lymphocytes in EBV positive and EBV negative nasopharyngeal carcinoma. Oral Oncol. 2017;71:16-25.

39. Hsu C, Lee SH, Ejadi S, Even C, Cohen RB, Le Tourneau C, Mehnert JM, et al. Safety and Antitumor Activity of Pembrolizumab in Patients With Programmed DeathLigand 1-Positive Nasopharyngeal Carcinoma: Results of the KEYNOTE-028 Study. J Clin Oncol. 2017;35(36):4050-4056.

40. Ma BBY, Lim WT, Goh BC, Hui EP, Lo KW, Pettinger A, Foster NR, et al. Antitumor activity of nivolumab in recurrent and metastatic nasopharyngeal carcinoma: an international, multicenter study of the Mayo Clinic phase 2 consortium (NCI-9742). J Clin Oncol. 2018;36(14):14121418.

41. Hong S, Zhang L. Gemcitabine improves survival in pa- tients with recurrent or metastatic nasopharyngeal carcinoma. Chin J Cancer. 2016;35(1):100.

42. Sharabi AB, Nirschl CJ, Kochel CM, Nirschl TR, Francica BJ, Velarde E, Deweese TL, et al. Stereotactic radiation therapy augments antigen-specific PD-1-Mediated antitumor immune responses via cross-presentation of tumor antigen. Cancer Immunol Res. 2015;3(4):345-355.

43. Yeo ELL, Li YQ, Soo KC, Wee JTS, Chua MLK. Combinatorial strategies of radiotherapy and immunotherapy in nasopharyngeal carcinoma. Chin Clin Oncol. 2018;7(2):15.

44. Song X, Shao Y, Jiang T, Ding Y, Xu B, Zheng X, Wang $Q$, et al. Radiotherapy Upregulates Programmed Death Ligand-1 through the Pathways Downstream of Epidermal Growth Factor Receptor in Glioma. EBioMedicine. 2018;28:105-113.

45. Gong X, Li X, Jiang T, Xie H, Zhu Z, Zhou F, Zhou C. Combined radiotherapy and Anti-PD-L1 antibody synergistically enhances antitumor effect in non-small cell lung cancer. J Thorac Oncol. 2017;12(7):1085-1097.

46. Finazzi T, Rordorf T, Ikenberg K, Huber GF, Guckenberger M, Garcia Schueler HI. Radiotherapy-induced anti-tumor immune response and immune-related adverse events in a case of recurrent nasopharyngeal carcinoma undergoing anti-PD-1 immunotherapy. BMC Cancer. 2018;18(1):395.

47. Cabezas-Camarero S, Puebla F, Subhi-Issa AI, SanzOrtega J, Perez-Segura P. Durable response to first-line nivolumab in a patient with oligometastatic PD-L1 positive nasopharyngeal cancer. Oral Oncol. 2018;87:204206.

48. Ooft ML, van Ipenburg JA, Sanders ME, Kranendonk M, Hofland I, de Bree R, Koljenovic S, et al. Prognostic role of tumour-associated macrophages and regulatory $\mathrm{T}$ cells in EBV-positive and EBV-negative nasopharyngeal carcinoma. J Clin Pathol. 2018;71(3):267-274.

49. Li J, Qian CN, Zeng YX. Regulatory T cells and EBV associated malignancies. Int Immunopharmacol. 2009;9(5):590-592.

50. Lin MC, Lin YC, Chen ST, Young TH, Lou PJ. Therapeutic vaccine targeting Epstein-Barr virus latent protein, LMP1, suppresses LMP1-expressing tumor growth and metastasis in vivo. BMC Cancer. 2017;17(1):18.

51. Louis CU, Straathof K, Bollard CM, Ennamuri S, Gerken C, Lopez TT, Huls MH, et al. Adoptive transfer of EBVspecific $\mathrm{T}$ cells results in sustained clinical responses in patients with locoregional nasopharyngeal carcinoma. J Immunother. 2010;33(9):983-990.

52. Chia WK, Teo M, Wang WW, Lee B, Ang SF, Tai WM, Chee CL, et al. Adoptive T-cell transfer and chemotherapy in the first-line treatment of metastatic and/or locally recurrent nasopharyngeal carcinoma. Mol Ther. 2014;22(1):132-139. 